\title{
La vigencia en el tipo de las Sentencias de Unificación, y los cambios Jurisprudenciales en la Jurisdicción Contencioso Administrativo: Un asunto en construcción
}

The validity in time of the unification judgments, and the jurisprudential changes in the administrative contentious jurisdiction: a matter under construction

$\mathrm{X}$

DOI: https://doi.org/10.21803/penamer.14.27.306

Carlos Enrique Ardila Obando

https://orcid.org/0000-0003-0979-847X

¿Cómo citar este artículo?

Ardila, C. (2021). La vigencia en el tipo de las Sentencias de Unificación, y los cambios Jurisprudenciales en la Jurisdicción Contencioso Administrativo: Un asunto en construcción. Pensamiento Americano, 14(27), 17-37. DOI: https://doi.org/10.21803/ penamer.14.27.306

\section{Resumen}

Introducción: Con la consolidación de la jurisprudencia como fuente formal de nuestro sistema de fuentes, se ha generado la necesidad de precisar los efectos en el tiempo de las sentencias de unificación y los cambios jurisprudenciales, de tal forma que se puedan armonizar las tensiones entre la seguridad jurídica y la justicia material. Objetivo: lo que supone definir si la expedición de una sentencia de unificación - la realización de un cambio jurisprudencial tienen efectos hacia el futuro-efecto prospectivo-, o si los efectos son de aplicación inmediata a los procesos administrativos o judiciales en curso-efecto retroactivo-; frente a esta disyuntiva jurídica, la jurisprudencia de la Jurisdicción Contenciosa Administrativa ha venido abordando esta problemática, ante la ausencia de una regulación legal y la falta de análisis por parte de la doctrina. Método o Metodología: se realiza un análisis descriptivo de las decisiones de la Jurisdicción Contenciosa Administrativa que han abordado el problema objeto de estudio, para partir de allí, inferir o deducir algunas reglas que subyacen en las decisiones estudiadas Resultados y conclusiones: finalizando con un análisis crítico de algunas de ellas, proponiendo alternativas para conciliar los principios de seguridad jurídica y justicia material.

Palabras Clave: Sentencias de unificación; Cambios jurisprudenciales; Efecto retroactivo; Efecto prospectivo; Confianza legítima; Seguridad jurídica; Justicia material.

\begin{abstract}
Introduction: With the consolidation of jurisprudence as a formal source of our system of sources, the need has been generated to specify the effects over time of the unification sentences and the jurisprudential changes, so that the tensions between the legal certainty and material justice. Objective: can be harmonized which means defining whether the issuance of a unification sentence or the realization of a jurisprudential change have effects in the futureprospective effect-, or if the effects are of immediate application to administrative processes or judicial in progress-retroactive effect-; Faced with this legal dilemma, the jurisprudence of the Contentious Administrative Jurisdiction has been addressing this problem, in the absence of legal regulation and the lack of analysis by the doctrine.
\end{abstract}


Method or Methodology: a descriptive analysis of the decisions of the Contentious Administrative Jurisdiction that have addressed the problem under study is carried out, to start from there, infer or deduce some rules that underlie the studied decisions. Results and conclusions: ending with an analysis critical of some of them, proposing alternatives to reconcile the principles of legal security and material justice.

Keywords: Unification sentences; Jurisprudential changes; Retroactive effect; Prospective effect; Legitimate trust; Legal security; Material justice.

\section{Resumo}

a

Palavras-chave: a

\section{Perfiles}

Abogado de la Universidad Santo Tomás, con especialización en derecho administrativo de la misma Universidad y en Derecho Ambiental de la Universidad Externado, Máster en Argumentación Jurídica de la Universidad de Alicante y Derecho de Daños de la Universidad de Girona, actualmente es Magistrado del Tribunal Administrativo del Meta. 


\section{Introducción}

El objetivo del presente artículo es abordar la problemática que se ha suscitado con los efectos en el tiempo de las sentencias de unificación y los cambios jurisprudenciales en la Jurisdicción Contenciosa Administrativa, derivado del reconocimiento de la fuerza vinculante tanto para las autoridades administrativas como judiciales de la jurisprudencia de las altas cortes, y las respuestas que a tal problema se han construido desde la jurisprudencia del Consejo de Estado, con un enfoque crítico y con aportes pensando en un desarrollo legislativo o jurisprudencial a futuro.

A efectos de realizar lo indicado en el párrafo anterior, en una primera parte, en el artículo se realizará un pequeño análisis histórico del valor normativo de la jurisprudencia desde los inicios de nuestro sistema jurídico hasta nuestros días, sus características tal y como se comprenden hoy en nuestro sistema jurídico.

Precisado lo anterior, se analizará brevemente los desarrollos teóricos sobre cuáles deben ser los efectos en el tiempo de los cambios jurisprudenciales y las sentencias de unificación, precisando los argumentos a favor y en contra de las diversas soluciones que se han propuesto.

Posteriormente, se analizará el desarrollo jurisprudencial que al interior del Consejo de Estado ha suscitado este problema jurídico, a partir del estudio de diversos asuntos que han sido resueltos por esta corporación y en donde se ha visto abocada a tomar postura frente al tema analizado.

Para finalizar, se intentará hacer una abstracción de los asuntos resueltos por el Consejo de Estado, a fin encontrar unas reglas o principios que excedan la casuística y permitan establecer unos patrones o normas que puedan hacer claridad, o, por lo menos, generar luces sobre el camino a seguir para abordar el tema objeto de estudio, para concluir con algunas propuestas para ser tenidas en cuenta o ser debatidas en el escenario académico o judicial.

\section{Desarrollo histórico del valor normativo de la jurisprudencia}

El sistema jurídico colombiano encuentra sus raíces en lo que se ha denominado el sistema romano-germánico, cuya característica definitoria es que la fuente principal y primordial del sistema jurídico es la Ley, constituyéndose la jurisprudencia en un elemento o criterio auxiliar de los jueces y en general de los operadores jurídicos. Por el contrario, los países de tradición anglosajona, o de common law, dan prevalencia a la jurisprudencia como fuente principal del sistema jurídico, razón por la cual han desarrollado toda una teoría sobre el valor del precedente (Ajani, 2010).

El antecedente más remoto del valor normativo de la jurisprudencia en el sistema se encuentra en la Ley 61 de 1886, cuyo artículo 39 introdujo en nuestro ordenamiento jurídico el concepto de doctrina legal, cuando dispuso que: "es doctrina legal la interpretación que la Corte Suprema de a unas mismas leyes en tres decisiones uniformes” (Ley 61,1886).

El valor normativo se deriva de la obligación que se imponía a los jueces de aplicar la doctrina legal para aquellos casos dudosos, con lo cual la jurisprudencia adquiere un valor más allá del criterio auxiliar propio de un sistema de derecho continental o de tradición romanista.

En el año de 1887 se expide la Ley 153, que en sus artículos 4, 8, y 10 profundizó en el valor normativo de la jurisprudencia, estableciendo las nociones de doctrina constitucional, doctrina legal más probabley las reglas de la jurisprudencia, lo que en términos del exmagistrado del Consejo de Estado y profesor Danilo Rojas Betancourth:

Éstos últimos agregados normativos, dejan ver dos importantes cambios respecto a lo señalado con anterioridad. En primer lugar, se introduce la expresión "regla de jurisprudencia" para el mejor entendimiento constitucional. Y quizá por ello mismo se introduce la nueva noción de "doctrina constitucional" con categoría normativa y orientadora, a su turno, de la 
interpretación legal. Una suerte de círculo virtuoso: la Corte Suprema interpreta la Constitución y genera reglas que retroalimentan la interpretación constitucional, con lo que a su vez se fortalece la interpretación legal. Y, en segundo lugar, la analogía judicial establecida anteriormente en la Ley 61 de 1886, sufre un vuelco a favor de la analogía legal, sin que del todo haya desaparecido aquella, pero ahora bajo el nombre de doctrina constitucional. Como se ve, se trata de una "jerarquía de analogías": primero se impone aplicar la analogía legal y luego la judicial, por cierto, con carácter obligatorio. (Rojas, 2018, p. 4)

Una consecuencia del carácter normativo de la jurisprudencia fue el establecimiento de una causal de casación, por el desconocimiento de la doctrina legal prevista en el artículo 369 numeral 1 de la Ley 105 de 1890, ley que además modificó de manera cuantitativa el concepto de doctrina legal en cuanto indicó que "es doctrina legal la interpretación que la Corte Suprema de justicia realiza a las misma leyes en dos decisiones uniformes" (Ley 105, 1890, art.368), con lo cual el concepto de doctrina legal se redujo de tres a dos decisiones uniformes.

El alcance de este concepto de doctrina legal se tornó rígido en cuanto a la posibilidad de ser modificado, a tal punto que se pensó que la variación de esta doctrina sólo era posible por vía legislativa; y de allí que se hubiese expedido la ley 169 de 1896, que en su artículo 4 consagró:

tres decisiones uniformes dadas por la Corte $\mathrm{Su}-$ prema como Tribunal de Casación sobre un mismo punto de derecho constituyen doctrina probable y los jueces podrán aplicarla en casos análogos, lo cual no obsta para que la Corte varíe la doctrina en caso de que juzgue erróneas las decisiones anteriores. (Ley 169, 1896)

La nueva redacción añadió el adjetivo probable a la doctrina legal, y dejó claro que la Corte Suprema podía variar la doctrina probable cuando la considerase errónea, con lo cual algunos indican que se dio paso al sistema de jurisprudencia libre (Armenta, 2014, p. 49). Lo que sí resulta claro de esta modificación es que se flexibiliza la aparente rigidez del sistema de doctrina legal, de allí que a partir de esta modificación se convirtió en probable, lo que permitía su modificación posteriormente.

Siguiendo en este desarrollo histórico al profesor Rojas Betancourth (2018) tuvieron que pasar setenta años para que una nueva norma sobre el efecto normativo de la jurisprudencia fuera expedida, en el artículo 13 del acuerdo 2 de 1971-reglamento del Consejo de Estado-, al definir para efectos de lo señalado en el artículo 24 del decreto ley 528 de 1964 jurisprudencia como dos decisiones uniformes sobre un mismo punto de derecho proferidas por cualquiera de las salas o secciones.

En el año de 1989, el decreto ley 2304 incorporó al Código Contencioso Administrativo el recurso extraordinario de súplica, para revocar las decisiones de las diferentes secciones del Consejo de Estado que, sin la aprobación de la Sala Plena, se acoja a doctrina contraria a la jurisprudencia de la Corporación.

En estas circunstancias normativas fue expedida la Constitución Política de 1991, la cual dentro de su articulado no previó disposición alguna sobre el carácter vinculante de la jurisprudencia, y quizás, por el contrario, el artículo 230 reiteró los orígenes continentales de nuestro sistema jurídico al precisar que "Los jueces, en sus providencias, sólo están sometidos al imperio de la Ley. La equidad, la jurisprudencia, los principios generales del derecho y la doctrina son criterios auxiliares de la actividad judicial” (Const, 1991, art.230).

Muy temprano la Corte Constitucional inició a estructurar y desarrollar la tesis del precedente judicial-término hasta ese momento desconocido en nuestro sistema-, y en la sentencia C-104 de 1993 señaló el carácter unificador de las jurisprudencia de las altas cortes y la necesidad de garantizar la vigencia del principio de igualdad, previsto en el artículo 13 de la Constitución, a través de una aplicación uniforme de la jurisprudencia, sin que de manera clara se precisará una conceptualización sobre el precedente en

Pensamiento Americano Vol. 14 - No. 27 - p.p. 17-37 • 2021 • Enero - Junio · Corporación Universitaria Americana • Barranquilla, Colombia · ISSN-e: 2745-1402 $\mathrm{http} / / /$ publicaciones.americana.edu.co/index.php/pensamientoamericano/index 
nuestro ordenamiento jurídico. Será en la sentencia SU-047 de 1999, en donde la Corte Constitucional sistematice por primera vez la noción de precedente, su alcance e impacto en el derecho colombiano, aludiendo a conceptos como los de obiter dicta, ratio decidendi.

Con posterioridad, la Corte, en la sentencia C-836 de 2001, reafirmó y profundizó el alcance de la vinculatoriedad de la jurisprudencia como fuente del derecho y la necesidad de su coherencia en el marco de un Estado Social de Derecho.

En el desarrollo de esta línea de pensamiento jurídico, la Corte Constitucional profundizó en la implantación de un concepto de precedente vinculante relativo en nuestro ordenamiento jurídico, para lo cual desarrolló los conceptos de precedente vertical, horizontal, y las cargas de argumentación, transparencia que cualquier juez tiene el deber de asumir, cuando se quiere apartar o separar del precedente vinculante.

Aunque aún persisten discusiones sobre el concepto y alcance del precedente, es posible concluir que a nuestro ordenamiento jurídico ya se integró el concepto de vinculatoriedad de la jurisprudencia como fuente formal del derecho, y quizás la mejor prueba de ello es que el legislador ha incorporado en diversos textos legales el desarrollo jurisprudencial que la Corte Constitucional ha consolidado tal y como de manera sintética se expuso.

En efecto, en el año 2010 se expidió la Ley 1395 de 2010, la cual en sus artículos 114 y 115 por primera vez incorporó en un texto normativo el concepto de precedente, con posterioridad la ley 1437 de 2011 (Código de Procedimiento Administrativo y de lo Contencioso Administrativo) en sus artículos 10, 102, 269, 270, estableció una regulación sistemática del precedente jurisprudencial tanto de manera sustancial como procesal en la Jurisdicción de lo Contencioso Administrativo.

No obstante, un tema sobre el precedente y su aplicación ha pasado inadvertido tanto para la doctrina como para la jurisprudencia-al menos hasta no hace poco tiempo- y este es: la vigencia en el tiempo de las sentencias de unificación y los cambios jurisprudenciales.

En efecto, resulta extraño que, por ejemplo, la obra del profesor Diego López Medina (2006), cuyo eje central ha girado entorno al precedente y su implementación en nuestro orden jurídico, haya omitido de manera sistemática un análisis de este tópico, que, como se verá, resulta relevante y tiene una incidencia directa en la vigencia de principios fundamentales del Estado Social de Derecho. Incluso, de manera reciente, se ha publicado un completo estudio sobre el precedente en materia de la jurisdicción contenciosa administrativa, y en dicho libro tampoco se hace un análisis integral de la vigencia en el tiempo del precedente.

\section{La Teoría jurídica y la dogmática frente a la vigencia en el tiempo de los precedentes y los cambios jurisprudenciales}

En este apartado se analizarán algunos planteamientos teóricos que desde la teoría jurídica y la dogmática se han realizado para abordar el problema de la vigencia en el tiempo de los precedentes o los cambios jurisprudenciales.

En primer lugar, debe indicarse que, prima facie, es posible establecer dos alternativas para solucionar el problema de la vigencia en el tiempo de los precedentes: de un lado, que el precedente o su cambio tenga efectos retroactivos, o, que, por el contrario, sus efectos sean prospectivos, y entre estas dos opciones es posible construir posibilidades eclécticas que tomen aspectos de una u otra solución como se verá más adelante.

La solución retroactiva supone que el precedente o su variación se aplica a todas las situaciones o actuaciones en curso, con independencia que al momento de haberse presentado la demanda o haberse iniciado la actuación administrativa no existiera el precedente o su variación.

Pensamiento Americano Vol. 14 - No. 27 - p.p. 17-37 • 2021 • Enero - Junio • Corporación Universitaria Americana · Barranquilla, Colombia • ISSN-e: 2745 -1402 
Por el contrario, la solución prospectiva señala que la regla- o subregla según nuestra terminología local- solo se aplica a los hechos, actuaciones administrativas o procesos judiciales que se inicien con posterioridad a la misma.

Como se puede advertir, entre estos dos planteamientos existe una tensión entre principios y derechos que resultan determinantes en los estados democráticos constitucionales como lo son: la igualdad, la seguridad jurídica, la buena fe, la confianza legítima, justicia material, todos consagrados o derivados de la Constitución Política de 1991.

Quienes defienden que los precedentes, o sus cambios, deben tener una vigencia prospectiva, argumentan en su favor que los principios de seguridad jurídica e igualdad lo imponen, pues no es posible que se sorprenda a los partes en contienda dando aplicación una "regla" que no estaba vigente al momento en que el conflicto se presentó o se inició el proceso judicial. El derecho, argumentan, debe generar previsibilidad y estabilidad en las relaciones que se regulan por él, por lo que sorprender a los sujetos iría en contra de la esencia de la función del derecho y se desconociera la seguridad jurídica que no es un principio meramente formal, pues a él subyace la garantía de la autonomía de la persona, en la medida que un sujeto de derecho puede diseñar un plan o proyecto de vida, una vez tenga certeza de las reglas claras que el derecho establece para desarrollarlo.

Además de lo anterior, el efecto prospectivo garantiza la vigencia del derecho fundamental a la igualdad, toda vez que procesos iniciados bajo la misma regla por personas diferentes serán definidos bajo la misma ratio jurisprudencial.

A esta idea del efecto retrospectivo del precedente o su cambio, le subyace una postura de filosofía del derecho, según la cual el juez es creador del derecho y en no pocas ocasiones tiene una función constitutiva y no declarativa del derecho, de tal forma que cuando interpreta el derecho-o más técnicamente una disposición-el resultado final es una norma cuya vigencia sólo puede regir relaciones jurídicas surgidas con posterioridad a su definición o establecimiento en la decisión correspondiente.

La profesora Gascón (2015) afirmó lo siguiente:

Por otro lado, la tesis de la revocación prospectiva de los precedentes suele ser relacionada con la teoría creativa del derecho judicial. Esta teoría hace énfasis en el papel que juega la discreción del juez en el litigio, y, en pocas palabras, acerca de la facultad de crear derecho del poder judicial. Luego-se sostiene- "el nuevo criterio jurisprudencial" constituye de cierta manera, una nueva norma, por tanto, debería tener efectos prospectivos. (p 93.)

Como más adelante se analizará, este planteamiento ha sido aceptado por lo menos en una decisión de la Sección Tercera del Consejo de Estado tal y como hasta ahora se ha indicado.

Por el contrario, aquellos que plantean la necesidad de darle efectos retroactivos al establecimiento de un precedente o su cambio, arguyen que el derecho no puede ser estático y que resulta inherente a su función que se adapte a los cambios de la sociedad, y ofrezca nuevas respuestas a los conflictos o relaciones entre los diversos sujetos sobre los que opera el derecho. Precisan, que la justicia material debe primar sobre la seguridad jurídica, en la medida en que el nuevo criterio al variar el anterior, pone en evidencia que resulta más acorde a la realidad jurídica el nuevo precedente, poniendo en evidencia las razones por las cuales el anterior no resulta satisfactorio o correcto jurídicamente, por lo que resultaría manifiestamente injusto decidir un caso con la convicción que el criterio a aplicar no es el más adecuado a la realidad social y jurídica.

$\mathrm{Al}$ igual que para la anterior postura, a este planteamiento de la aplicación retroactiva del precedente o su variación, le subyace una postura filosófica; sobre el particular Rojas (2018) lo sintetiza en los siguientes términos:

En la perspectiva según la cual los jueces son in-

Pensamiento Americano Vol. 14 - No. 27 - p.p. 17-37 • 2021 • Enero - Junio · Corporación Universitaria Americana • Barranquilla, Colombia · ISSN-e: 2745-1402 http://publicaciones.americana.edu.co/index.php/pensamientoamericano/index 
térpretes de normas jurídicas y, en esa medida, solo fijan sus alcances y efectos, se ha entendido que las reglas jurisprudenciales que extraen de sus decisiones son declarativas y no constitutivas y, por lo tanto, tienen la misma vigencia de las normas interpretadas; de allí que, cuando se observan cambios jurisprudenciales a partir de una reinterpretación de las normas vigentes, se considera implícitamente que la nueva regla jurisprudencial es aplicable tanto al caso por virtud del cual se realiza el cambio, como a los que se resuelvan con posterioridad, por respeto al precedente judicial, garantía derivada del derecho a la igualdad. Lo anterior aun cuando se trata de sentencias de unificación jurisprudencial cuya fuerza jurisprudencial es mayor en tanto cumplen la función especial y específica de ordenar y clarificar el precedente aplicable. (p. 20)

Además de lo anterior, esta postura implica aceptar que existe un riesgo propio de todo sistema jurídico que se materializa en el cambio jurídico que una postura jurisprudencial puede tener y que se debe aceptar para que el sistema funcione de manera integral.

En la teoría, las propuestas de solución a este problema no han sido unívocas, ni su fundamentación similar, y por el contrario se diría que pareciera no existir un consenso en torno a cuál es el mejor camino a seguir.

Así, por ejemplo, el profesor Sodero (2004), en el artículo citado, concluye después de un análisis de los dos planteamientos-efecto retroactivo, efecto prospectivo-, que no resulta plausible exigir una respuesta categórica y que, por el contrario:

Más allá de la materia concreta que se trate, y de encuestas en la jurisprudencia y en la literatura, nuestra tesis es que ninguna fórmula podrá expresar suficientemente la respuesta para esta problemática, y por ello parece forzoso concluir en qué será el juicio prudencial del juez el que ha de determinar en cada caso la alternativa más justa hic et nunc, a partir de ponderar "los méritos y deméritos en cada caso” (según la fórmula ya cita- da de "Linklletter V. Walker"), teniendo en claro que la cuestión no deber ser gobernada por concepciones metafísicas sobre la naturaleza del judge-made law, ni por el fetiche hacia algún dogma implacable como el de la división de poderes gubernamentales, sino (...) por el más profundo sentido de justicia, que exige evitar las "consecuencias sustancialmente inequitativas”. (p 250)

En contravía de este planteamiento, la profesora Gascón (2015) criticando el mismo, asume una postura diversa y propone un criterio definitorio sobre los efectos en el tiempo de los cambios jurisprudenciales en el concepto de favorabilidad.

En sus palabras:

En conclusión, los efectos del cambio de la jurisprudencia se rigen por el principio de universalidad (que requiere retroactividad) y por el principio de seguridad jurídica (que requiere limitar la retroactividad cuando la aplicación del nuevo criterio conlleva consecuencias más restrictivas que la aplicación de precedente). Entonces, si el nuevo criterio es más favorable o menos restrictivo que el previo, este será aplicado retroactivamente. Si es menos favorable o más restrictivo, este será aplicado prospectivamente. (p.93)

Finalmente, no podía dejar de señalarse la experiencia de la Corte de Casación Francesa que decidió encargar a un renombrado profesor universitario, realizar un reporte sobre los efectos de los cambios jurisprudenciales y los mecanismos para reducir sus impactos, que concluyó con el Reporte Molfessis se concluyó que era recomendable como regla general que los cambios jurisprudenciales debían operar de manera retroactiva, sin embargo, para algunos supuestos era más plausible el postergar los efectos del cambio jurisprudencial (Molfessis, 2005).

En un sintético trabajo realizado por Zejalbo (2012), se analiza este problema desde la perspectiva del derecho europeo continental donde se llega a la conclusión que la regla general es aplicación retroac- 
tiva de la jurisprudencia, norma que debe ser matizada en aquellos eventos en que se sacrifiquen valores con una especial protección constitucional.

\section{Análisis de la jurisprudencia del Consejo de Estado respecto de la vigencia de los cambios ju- risprudenciales y las sentencias de unificación}

Tal y como lo indica el profesor Rojas Betancourth (2018), en nuestro derecho históricamente la regla general ha sido la aplicación retroactiva de la jurisprudencia, pese a lo cual tal regla ha venido siendo objeto de análisis y estudio por parte de la jurisprudencia, en especial de la Contenciosa Administrativa, sobre la que en este apartado se analizará el desarrollo reciente.

La moderación o modulación de esta regla general ha tenido su evolución a partir de la fuerza normativa que la Constitución de 1991 les dio a los derechos fundamentales, entre ellos el derecho a la igualdad, el debido proceso, la buena fe y la confianza legítima, vigorizados por los desarrollos jurisprudenciales de la Corte Constitucional.

En los siguientes párrafos, se analizarán diversas sentencias proferidas por el Consejo de Estado, en las que ha abordado el tema de la vigencia en el tiempo de las sentencias de unificación y los cambios jurisprudenciales, agrupadas por diversos ejes temáticos.

Un primer grupo de decisiones abordaron asuntos de naturaleza procesal, siendo quizás la sentencia hito la Sentencia No. 7600012331000200002513/2007, en la cual, desde la perspectiva procesal, se discutía si la acción procedente para reclamar la sanción moratoria por el no pago oportuno de las cesantías era la de reparación directa o la nulidad y restablecimiento del derecho, concluyéndose que la vía procesal adecuada era esta última, pese a lo cual señaló que los procesos que ya se hubieren iniciado bajo la cuerda procesal de la reparación deberían continuar su trámite y ser decididos de fondo, dando aplicación a los principios de seguridad jurídica y de acceso a la administración de justicia, con lo cual los efectos procesales de esta decisión tuvieron el carácter de prospectivos. Con posterioridad, esta tesis se reiteró en la Sentencia No. 19.957/2011.

En esta misma línea de pensamiento, respecto de aspectos procesales y la aplicación prospectiva del precedente o su variación, la Sentencia No. $11001031500020150003100 / 2015$ en sede de Juez de tutela amparar los derechos fundamentales del accionante, a quien el Tribunal Administrativo del Valle le había declarado la nulidad del proceso por falta de jurisdicción, dando aplicación a la SU No. 17859/2013, y según la cual cuando se pacte en un contrato estatal una cláusula compromisoria sólo es posible deshacer la misma por un documento escrito que deje sin efectos la mencionada cláusula, variando la postura anterior de la derogatoria tácita de la disposición compromisoria cuando presentada la demanda por una de las partes, la contraparte contesta la demanda sin proponer la excepción de la existencia de la cláusula compromisoria.

La Sección Quinta en Sentencia No. $11001031500020150003100 / 2015$ consideró que la variación de la tesis proferida por la Sección Tercera en la SU No. 17859/2013 debía tener efectos prospectivos, es decir, que se aplicaba para supuestos acaecidos con posterioridad a su expedición y como en el caso objeto de estudio, la demanda se había presentado con fecha anterior a la providencia de unificación, no era posible haberla aplicado, con lo cual se vulnera el derecho fundamental al debido proceso, debiéndose ordenar dejar sin efectos el auto en el que el Tribunal Administrativo del Valle declaró de nulidad y procediendo a definir de fondo el asunto.

En la citada providencia para justificar la decisión se indicó:

La variación de dicha regla afectó no sólo la comprensión que la comunidad tenía respecto de la renuncia tácita al pacto arbitral sino consecuencialmente, a los procesos en curso, en los que se declaró, como en el sub examine, nulidad por falta de jurisdicción. Claramente se modificó la situa- 
ción jurídica que la propia jurisdicción contenciosa venía aplicando a casos análogos y quebrantó la confianza y seguridad jurídica que se tenía sobre el particular.

La garantía que el principio perpetuatio jurisdictionis protege en el subjudice recae en el respeto de la certeza que se tenía sobre la jurisdicción a la que correspondía resolver el conflicto derivado del contrato estatal, ante una determinada eventualidad concretada en la renuncia tácita a la cláusula compromisoria, pues ésta se sustentaba en un precedente jurisprudencial imperante al momento de presentación de la demanda.

Sin bien es cierto la nueva tesis de la Sección Tercera plantea también una subregla jurídica en materia de jurisdicción, también lo es que ésta no tiene la entidad suficiente para modificar, como lo haría el contenido de una ley, el alcance de lo que constituye "jurisdicción”, luego no puede afectar aquello que el referido principio pretende proteger.

Significa lo anterior, que el abrupto cambio jurisprudencial, no debió afectar a aquellas demandas que se interpusieron en ejercicio de la acción de controversias contractuales antes del auto de unificación y en las que no se propuso como excepción la de "cláusula compromisoria”, puesto que estas se incoaron en el momento en que la jurisprudencia acepta la referida renuncia tácita.

Dos ejemplos adicionales que ayudarán a entender los criterios manejados por el Consejo de Estado respectodelpuntoenanálisis,elprimerosematerializóen la Sentencia No. 11001031500020160318100/2017, en la cual al resolver un recurso extraordinario de revisión en el cual uno de los temas centrales era la caducidad de la acción, encontró que la Sección Tercera había aplicado un criterio que no estaba vigente al momento de presentarse la demanda, que hacía variar el inicio del cómputo del plazo de la caducidad, pues inicialmente esta sección interpretó que el registro presupuestal perfeccionaba el contrato estatal y por ende desde allí se debía empezar a con- tar el plazo, y con posterioridad varió su postura para afirmar que bastaba la firma del contrato estatal por las partes para entenderlo perfeccionado, por lo que desde allí debía contarse el término. En virtud de lo anterior, la Sala Especial de Revisión estimó que para efectos de la caducidad debía aplicarse la tesis vigente al momento de presentarse la demanda, lo que es lo mismo que señalar que la variación del precedente tiene efectos hacia el futuro, porque: cuando hay una interpretación dada por el órgano de cierre, relacionada con el momento a partir del cual se comienza a contar, es claro que ese precedente es obligatorio hasta que sea formalmente modificado, y por tanto no se puede de manera posterior aplicar un cambio interpretativo, puesto que eso no solo afecta la seguridadjurídica, sino el acceso a la administración de justicia y el derecho a la igualdad.

El segundo caso, es el relacionado con la capacidad procesal de los consorcios y uniones temporales para concurrir al proceso de manera directa sin necesidad de vincular a los miembros integrantes de estas figuras asociativas. Hasta el año 2013, la Sección Tercera del Consejo de Estado sostenía que los consorcios y uniones temporales no tenían capacidad para comparecer al proceso, por lo que debía demandarse a las personas naturales o jurídicas integrantes de los mismos, so pena de que se profiera una sentencia inhibitoria, lo que cambió con la Sentencia No. 2500023260001997139300/2013 , en la cual se precisó que los consorcios y las uniones temporales si tenían capacidad procesal por lo no había lugar a decisiones inhibitorias y sobre estos contratos de asociación podían recaer directamente pretensiones, cambio jurisprudencial que se aplicó de manera retroactiva.

En contravía de estos planteamientos, en reciente decisión la Sala Plena de la Sección Tercera del Consejo de Estado en SU No. 61033/2020 unificó su postura respecto al término de caducidad del medio de control de reparación directa por pretensiones relacionadas por delitos de lesa humanidad y crímenes de guerra, definiendo la controversia, hasta ese momento existente, entre quienes consideraban que para es-

Pensamiento Americano Vol. 14 - No. 27 - p.p. 17-37 • 2021 • Enero - Junio · Corporación Universitaria Americana • Barranquilla, Colombia • ISSN-e: 2745-1402 http://publicaciones.americana.edu.co/index.php/pensamientoamericano/index 
tos supuestos no operaba la caducidad y quienes estiman que por regla general debía operar el término de dos años, postura esta última que fue acogida por el pleno de la Sección Tercera, sin que en el texto de la providencia se hubiera precisado que los proceso en trámite, o los presentados con anterioridad a este decisión se debían regir por la tesis anterior.

Un segundo grupo de decisiones se concentraron en asuntos de naturaleza laboral, en especial se abordó el tema del ingreso base liquidación y las factores salariales a tener en cuenta respecto a las personas que era beneficiarias del régimen de transición establecido en el artículo 36 de la Ley 100 de 1993, pues existían dos tesis opuesta: de un lado, la Corte Constitucional, en especial desde la SU-230/15, sostenía que las personas que era beneficiarias del régimen de transición se les debía aplicar el ingreso base de liquidación-IBL- conforme a la Ley 100 de 1993, es decir, con el promedio de los devengado en los últimos 10 años y teniendo solo en cuenta los factores salariales sobre los que se habían realizado cotizaciones; de otra parte, la Sección Segunda del Consejo de Estado sostenía que el IBL era el del régimen anterior, es decir, el promedio de lo devengado en el último año y sobre la totalidad de factores devengados en ese año, con independencia de si sobre los mismos se había o no realizado cotizaciones.

En el contexto de esta discusión, se profirieron varias sentencias que analizaron el tema de la vigencia en el tiempo de los cambios jurisprudenciales, debido a múltiples tutelas que se presentaron con las decisiones judiciales de los Tribunales Administrativos.

Así,enSentencia No. 1100010315000201600038/ 2016, la Sección Cuarta del Consejo de Estado en sede de tutela señaló que la ratio iuris de la sentencia SU230/15 solo aplicaba para demandas presentadas con posterioridad a esta decisión, es decir, después del 29 de abril de 2015, con lo que se precisaba que esta decisión tenía efectos prospectivos y en consecuencia demandas presentadas con anterioridad eran decididas con fundamento en la tesis de la Sección Segunda y las iniciadas con posterioridad con la tesis de la Corte.
En esta misma línea, la Sección Cuarta profirió varias decisiones, siendo el principal argumento el indicar que la regla establecida en la SU-230/15 era una fuente formal del derecho y en consecuencia regía como las leyes hacia el futuro.

Por su parte, la Sección Quinta del Consejo de Estado, en sede de tutela, a través de la Sentencia 100103150002016013440/2016, y en contra de la tesis de la Sección Cuarta, señaló que la sentencia SU$230 / 15$, era aplicable a todos los procesos en curso, pues la decisión de la Corte tenía efectos inmediatos sin que ellos supusiera vulneración a derecho alguno, toda vez que mientras un proceso está en curso, el actor tan solo tiene una mera expectativa y no un derecho, el cual solo se consolida cuando la decisión final queda ejecutoriada.

En una sentencia particular Sentencia T- 645/16, una sala de revisión de la Corte Constitucional dando alcance a la vigencia en el tiempo de la SU-230 de 2015, planteó una nueva hipótesis de vigencia de la regla contenida en la mencionada decisión, según la cual el precedente aplicable era el que estaba vigente al momento en que se causó el derecho, es decir, cuando se cumplieron los requisitos de edad y tiempo. No obstante, la Sala Plena de la Corte Constitucional, por auto 229 del 10 de mayo de 2017, declaró la nulidad de esta providencia por desconocer los mandatos de la sentencia C-258/13 y SU-230/15.

Como se debe haber advertido, existían múltiples criterios sobre la vigencia en el tiempo de la sentencia SU-230 de 2015, pues para algunos tenía efectos inmediatos, pero para otros el efecto era prospectivo, situación que vino a ser definida en reciente sentencia de unificación de la Sala Plena de lo Contencioso Administrativo (Sentencia No. 52001233300020120014301, 2018), en la cual acogiendo la tesis de la Corte Constitucional sobre el ingreso base de liquidación, precisó los efectos en el tiempo de esa decisión en los siguientes términos:

115. La Sala Plena de esta Corporación, por regla general, ha dado aplicación al precedente en forma

Pensamiento Americano Vol. 14 - No. 27 - p.p. 17-37 • 2021 • Enero - Junio · Corporación Universitaria Americana · Barranquilla, Colombia · ISSN-e: 2745 -1402 
retrospectiva, método al que se acudirá en esta sentencia, disponiendo que las reglas jurisprudenciales que se fijaron en este pronunciamiento se aplican a todos los casos pendientes de solución tanto en vía administrativa como en vía judicial a través de acciones ordinarias; salvo los casos en los que ha operado la cosa juzgada que, en virtud del principio de seguridad jurídica, resultan inmodificables.

116. Para la Sala, los efectos que se dan a esta decisión garantizan la seguridad jurídica y dan prevalencia a los principios fundamentales de la Seguridad Social, por ello no puede invocarse el principio de igualdad, so pretexto de solicitar la no aplicación de esta sentencia.

Si bien esta decisión tiene un efecto vinculante fuerte debido a la autoridad de quien la expidió, debe precisarse que no profundizó en las razones por las cuales debían prevalecer los efectos retroactivos sobre los prospectivos, dejando de considerar por lo menos una regla de relevancia constitucional, como más adelante se explicará.

Para finalizar el grupo de decisiones que han analizado, en asuntos laborales, los efectos en el tiempo de los cambios jurisprudenciales, debe indicarse que en un esfuerzo loable la Sección Segunda del Consejo de Estado ha proferido una serie de decisiones de unificación sobre temas en donde se presentaban diversas tesis, unificando las discrepancias en estos diversos temas y en todos ellas, con mucho mejor argumentación que la sentencia de la Sala Plena recién indicada, ha precisado que los efectos en el tiempo de las mismas son de naturaleza retrospectiva, pero reconociendo que en ciertos casos y supuestos los efectos podrían ser prospectivos.

Se lee en la decisión:

219. Así mismo, las diferentes Salas de esta Corporación han dado aplicación al precedente de forma retroactiva. Y solo en algunos casos, se determinó que la nueva regla aplicaba hacia el futuro, de manera que los casos anteriores debían definirse por los criterios vigentes. Estos son entre otros: i) en materia de comparecencia al proceso por parte de la Fiscalía General de la Nación a través del director ejecutivo de administración judicial o de la propia fiscalía; ii) la definición del extremo temporal inicial de la incompatibilidad prevista, para alcaldes y gobernadores, en los artículos 31.7 y 32 y 7 y 39 de la Ley 617 de 2000, el alcance de la aplicación de los principios pro homine y pro electoratem en materia electoral y los efectos de la declaratoria de nulidades electorales por vicios subjetivos. (Sentencia No. 2015-00051, 2017)

220. En ese orden, se concluye que la regla general es la retrospectividad de la jurisprudencia (retrospective overruling, adjudicative retroactivity) y que la excepción es la prospectividad (prospective overruling). Esta última hipótesis presupone la aplicación de un juicio de ponderación, que permita determinar cuál es la decisión que más efectiviza los principios constitucionales.

221. Ahora bien, a efectos de definir cuándo es procedente dar efectos prospectivos a una sentencia, es necesario tener en cuenta el caso «Desist v. United States (Sodero, 2004), donde la Corte recuerda que desde "Linkletter", quedó establecido que la Constitución no prohíbe ni exige el efecto retrospectivo para decisiones que contengan nuevas reglas constitucionales en materia de juicios criminales, siempre ha considerado la retroactividad o irretroactividad de tales decisiones en función de tres factores, "recientemente reseñados en Stovall v. Denno, 388 U.S. 293”, que importan tener en cuenta: a) el fin al cual sirven los nuevos standards, b) el grado de confianza sobre los viejos standards, y c) el efecto sobre la administración de justicia de la aplicación retroactiva de los nuevos standards»

222. Por su parte, esta Corporación en reciente decisión (Auto No. 0800123330002013004401, 2017) defendió la prospectividad del precedente cuando: i) las partes en un litigio hayan fundado sus pretensiones o defensa, según el caso, única y exclusivamente en el precedente vigente al momento de su actuación 
ante la jurisdicción; ii) lo bien fundado de dicho precedente no haya sido cuestionado en el trámite del proceso; y iii) el cambio opere en un estadio procesal en el que resulte imposible reconducir las pretensiones o replantear la defensa pues, en esas circunstancias, la aplicación de la nueva regla jurisprudencial no sólo sorprendería a las partes sino que, de facto y sin posibilidades de reformular los términos del litigio, dejaría sin sustento la posición jurídica defendida por una de ellas.

Es esta entonces la postura consolidada de la Sección Segunda del Consejo de Estado en el asunto que se ha venido analizando, y que se ha venido reiterando en las diversas sentencias de unificación que ha proferido la sección segunda, que valga la pena desde ahora resaltar si bien es similar al de la Sala Plena, difiere en cuanto reconoce las excepciones a la aplicación retrospectiva del precedente, señalando alguna reglas para la identificación de estas excepciones.

Un tercer grupo de casos, se corresponden con asuntos de índole electoral, en las cuales la Sección Quinta del Consejo de Estado ha fijado unas posturas y planteamientos consistentes en torno al tema de los efectos en el tiempo de las sentencias varían posturas jurisprudenciales sobre inhabilidades.

Tres decisiones han indicado que la (re)interpretación de una causal de inhabilidad realizada a través de una sentencia en la Sección Quinta que suponga una modificación a la regla que se venía sosteniendo tiene vigencia para procesos, hechos o actuaciones ocurridas con posterioridad a las respectivas decisiones judiciales, con lo cual el efecto otorgado a estas decisiones es de carácter prospectivo.

La Sección Quinta en Sentencia No. 25000233100020110077502/2013, al analizar la prohibición de la doble militancia prevista en la Ley 1475 de 2011 como causal de nulidad de los actos electorales, estableció que la vulneración de esta prohibición configuraba la causal de nulidad del acto administrativo de naturaleza electoral, pese a lo cual estimó que en el caso a decidir no podía aplicarse esta postura, pues su desarrollo y consolidación jurisprudencial solo ocurrió años después de los hechos y actos que eran objeto de juicio, por lo que en aplicación del principio de confianza legítima y el derecho a elegir y ser elegido.

En los términos de la decisión:

Lo discurrido obliga a concluir que los efectos de este fallo en cuanto al actual entendimiento de la figura no pueden tener efectos, más allá, de los académicos, so pena de desconocer la confianza legítima del Estado Juez y el derecho fundamental a ser elegido de quien hoy ostenta la calidad de demandado.

Con posterioridad, en Sentencia No. $11001032800020140003400 / 2015$, la misma sección, al analizar los extremos temporales de la inhabilidad prevista en el artículo 179 numeral 5 de la Constitución, indicó que la misma se entenderá configurada desde el día de la inscripción hasta día que efectivamente se declare la elección, modificando la lectura anterior, por lo que determinó que la misma no era aplicable al presente asunto, pues al momento de la elección el criterio jurisprudencial era otro, lo cual atentaría contra el principio de confianza legítima al ser un cambio abrupto e imprevisto, por lo que en lo que denominó jurisprudencia anunciada, en la parte resolutiva de la sentencia preceptúa:

SEGUNDO: ADVERTIR a la comunidad en general que las consideraciones expuestas en esta providencia respecto del entendimiento del factor temporal de la inhabilidad contemplada en el numeral $5^{\circ}$ del artículo 179 Constitucional tendrán aplicación desde las próximas elecciones de Senado y Cámara de Representantes, es decir, las concernientes al período 2018-2022.

Lo anterior constituye un claro ejemplo de aplicación prospectiva de un cambio o modificación jurisprudencial.

Para finalizar este grupo de providencias, en Sen-

Pensamiento Americano Vol. 14 - No. 27 - p.p. 17-37 • 2021 • Enero - Junio · Corporación Universitaria Americana • Barranquilla, Colombia · ISSN-e: 2745-1402 $\mathrm{http} / / /$ publicaciones.americana.edu.co/index.php/pensamientoamericano/index 
tencia No. 2015-00051/2016 la Sección Quinta consolidó esta línea jurisprudencial, al definir un asunto en el cual se modifica el extremo temporal de la incompatibilidad prevista para los alcaldes y gobernadores señalados en los artículos 31.7, 32 y 38.7 y 39 de la Ley 617 de 2000 que el nuevo alcance de la norma no podía operar para el asunto que era objeto de análisis y su aplicación sería prospectiva.

De manera reciente, la Sección Segunda Subsección A del Consejo de Estado en Sentencia No. 11001031500020190307901/2020, al resolver en sede de impugnación de tutela el conflicto suscitado por Ángela María Robledo, como consecuencia de la declaratoria de nulidad de su elección como senadora, al haber sido fórmula vicepresidencial de Gustavo Petro, ordenó tutelar a la Sección Quinta del Consejo de Estado por no haber analizado la aplicación del efecto prospectivo de la decisión, toda vez que estaba sentando jurisprudencia en un tema novedoso en las reglas del sistema democrático colombiano.

Por último, se analizará un grupo de sentencias que en principio no se puede etiquetar en un tema específico,y que talvez se debería ubicar como de derecho sustancial. Y, para ello, en primer lugar, resulta relevante la Sentencia No. 44001233300220160009601/2017, proferida por la Sección Primera, que al resolver la segunda instancia de un proceso por pérdida de investidura determinó que no se configuraba la causal alegada porque al momento en que el demandado se inscribió lo hizo con fundamento en una tesis jurisprudencial que entendía que las circunscripciones departamental y municipal no coincidían, por lo que el cambio jurisprudencial acaecido con posterioridad, que entendió que las circunscripciones sí coinciden, no puede justificar la imposición de una sanción como la pérdida de investidura, dando aplicación al principio de confianza legítima y dándole efectos prospectivos al cambio de jurisprudencia indicado.

La Sentencia No. 33945/2017, resulta particularmente especial, por abordar el tema que se ha venido estudiando desde la perspectiva del derecho de daños, y estableció que los perjuicios derivados de la muerte de una persona dedicada a las actividades del hogar excedían el solo perjuicio material del costo de pagar una persona que atendiera estas actividades materiales, y que incluía las actividades personalísimas de cuidado, afecto, englobando en el concepto de responsabilidades domésticas el daño a indemnizar que supone una afectación al derecho a tener una familia, por lo que además del daño material se debe indemnizar la afectación a este derecho constitucional, pese a lo cual en el asunto que era objeto de análisis decidió no condenar al pago de este perjuicio con la redefinición señalada, en razón que:

Como quiera que esta sentencia de unificación comporta una modificación jurisprudencial que tendría efectos en la tasación y liquidación de nuevos perjuicios frente a los cuales no operó el principio de contradicción, la Sala emplea la figura de la jurisprudencia anunciada y, por tal motivo, esta alteración del precedente sólo será aplicable a los procesos que se inicien con posterioridad a esta providencia, en aras de garantizar los principios constitucionales al debido proceso y a la defensa de las entidades y sujetos demandados ante esta jurisdicción.

La Sección Tercera del Consejo de Estado, en Sentencia No. 68001233100020090029501/2017 al analizar la nulidad de un acto administrativo que había declarado la caducidad de un contrato estatal por fuera del plazo de ejecución contractual, negó las pretensiones de la demanda, al considerar que al momento de expedirse el acto cuestionado, la tesis jurisprudencial vigente permitía declarar la caducidad a pesar de estar finalizado el plazo de ejecución, planteamiento que fue variado con posterioridad, señalando que el acto que declara la caducidad sólo puede ser proferido dentro del término de ejecución contractual, pero que tal circunstancia no era relevante en el presente asunto, porque esta última decisión tenía efectos prospectivos.

En la mencionada decisión, para fundamentar la tesis de los efectos prospectivos de la sentencia se indicó: 
4.4.- Esta Sala considera que una razonable aproximación a esa problemática desde un enfoque basado en derechos impone asumir una premisa fundamental: las buenas razones que impulsan el progreso del pensamiento jurídico, por la vía del cambio de jurisprudencia, no justifican que a costa de tal evolución sea legítimo y proporcional el sacrificio de los derechos de quienes obraron en el pasado movidos por lo que mandaba el antiguo precedente. Así, aun cuando no existe un derecho subjetivo de persona alguna de impedir la evolución y cambio de las soluciones que provea el derecho de fuente jurisprudencial, sí es razonable demandar que tales mutaciones sean respetuosas de los derechos subjetivos de los ajusticiados.

4.5.- Entonces, la garantía de los derechos individuales en el marco de las actuaciones administrativas y jurisdiccionales lleva a afirmar por regla general que todo cambio de jurisprudencia que altera de manera sustantiva el contenido y alcance de las competencias estatales, de los derechos de las personas o los mecanismos de protección de los mismos, necesariamente debe ser adoptado e interpretado con efecto prospectivo a futuro, esto es, que de manera ínsita se encuentra envuelto en él su radio de acción temporal o ratione temporis gobernando las situaciones problemáticas que se susciten a partir de la fecha posterior a su adopción, lo que excluye cualquier suerte de aplicación retroactiva del nuevo criterio jurisprudencial. (Negrilla y subrayado fuera de texto)

En muy reciente decisión, la Sección Tercera del Consejo de Estado, (Sentencia No. 39947, 2020), al estudiar un caso de reclamación de un particular a una entidad pública por la prestación de servicios sin que mediare vínculo contractual alguno, determinó que la tesis del enriquecimiento sin causa y el camino procesal de la reparación directa no aplicaban al asunto, toda vez que los hechos ocurrieron en los años 2003 y 2004 , habiendo sido proferida la sentencia de unificación en el año 2012. Al respecto se indicó:

26.- No obstante, lo anterior, la Sala confirmará la decisión de primera instancia en la cual se ordena el pago de los servicios prestados, por las razones que se señalan a continuación:

26.1.- La referida sentencia de unificación en la que se establece la regla conforme con la cual no es procedente formular una acción contractual e invocar el enriquecimiento sin causa, fue proferida mucho después de que ocurrieran los hechos objeto del presente proceso, que se refieren a la prestación de servicios en el lapso comprendido entre el $1^{\circ}$ de agosto de 2003 y enero 13 de 2004.

Como se advierte, en esta decisión una subsección en su totalidad adopta como regla general la vigencia prospectiva de los cambios jurisprudenciales, desarrollando los argumentos que justifican tal postura.

Analizadas las sentencias del Consejo de Estado que han abordado el tema objeto de estudio, corresponderá intentar conceptualizar los planteamientos realizados en estas providencias, para deducir de ellas, si es posible, unas reglas que permitan dar luz al desarrollo de un tema tan complejo, que supone una tensión permanente entre principios y valores constitucionales relevantes para la aplicación del derecho.

\section{Conceptualización de las decisiones del Conse- jo de Estado, reglas judiciales y análisis crítico}

Tal y como se indicó al inicio de este artículo, las posturas teóricas frente al tema de la vigencia en el tiempo de los cambios jurisprudenciales podían tener tres soluciones a saber: El efecto retroactivo-hacía el pasado-, el efecto prospectivo-hacía el futuro-, y el efecto ad-hoc, es decir que será en cada caso el juez quien defina si el efecto del cambio será retroactivo a prospectivo.

Lo primero que importa resaltar, es que no existe una norma jurídica derivada de un texto normativo que nos imponga el efecto a aplicar en el tiempo de las sentencias de unificación o los cambios jurisprudenciales, por lo que ha sido la jurisprudencia quien ha definido esta situación a través de diversas subreglas

Pensamiento Americano Vol. 14 - No. 27 - p.p. 17-37 • 2021 • Enero - Junio · Corporación Universitaria Americana • Barranquilla, Colombia · ISSN-e: 2745-1402 
jurisprudenciales como se ha descrito anteriormente.

Tal vez la única norma que dispone un mandato sobre los efectos en el tiempo de las decisiones judiciales es el artículo 45 de la (Ley 270, 1996), que señala que las sentencias de la Corte Constitucional producen efectos hacia el futuro, a excepción que la propia Corte disponga otra cosa, disposición que no fue tenida en cuenta en ninguna de las decisiones analizadas, ni siquiera para invocar una eventual aplicación analógica.

Tampoco en las decisiones estudiadas se pretendió dar aplicación a las normas que rigen la vigencia en el tiempo de la Ley, pues se puede inferir de las decisiones que se estudiaron, que la vigencia en el tiempo de las decisiones judiciales no puede seguir la misma lógica de los textos normativos, pues aquellas siempre presuponen la existencia de una norma previa a partir de la cual surge la nueva interpretación jurisprudencial.

Se puede afirmar que del plexo de decisiones analizadas, al interior del Consejo de Estado ha tomado mayor relevancia la idea que las sentencias de unificación y los cambios jurisprudenciales tienen por regla general un efecto retroactivo o para algunos retrospectivo, lo cual significa que una vez proferida la decisión, la misma debe aplicarse a todas las actuaciones en curso, sean administrativas o judiciales, sin que con ello se vulnere el principio de la seguridad jurídica o el derecho fundamental a la igualdad, y en esta línea es quizás la Sección Segunda quien más ha consolidado esta postura, a través de las diferentes sentencias de unificación que ha proferido, en las cuales siempre se hace un análisis de los efectos en el tiempo de la decisión tomada, reiterando el efecto prospectivo.

Lo anterior puede concluirse a partir que en reciente decisión de Sala Plena de lo Contencioso Administrativo (Sodero, 2004) al estudiar la vigencia en el tiempo la nueva regla jurisprudencial establecida se concluyó que el efecto debía ser retroactivo, con lo cual el máximo órgano de la Jurisdicción Contenciosa Administrativa integrado por todos los miembros de la Consejo de Estado con funciones judiciales, fijaron una subregla judicial que indica que los cambios jurisprudenciales y las sentencias de unificación producen efectos retroactivos.

Además de lo anterior, las diversas secciones del Consejo de Estado en las sentencias analizadas optaron mayoritariamente por los efectos retroactivos, con excepción quizás de las sentencias del 4 de septiembre de 2017, proferida por la subsección C de la Sección Tercera (Sodero, 2004) y la sentencia del 02 de marzo de 2020 de Subsección b de la misma Sección que se inclinó por los efectos prospectivos.

Si bien es cierto la sentencia de la Sala Plena de lo Contencioso Administrativo no ofreció mayores argumentos para justificar su decisión de dar efectos retroactivos a su decisión, de las diversas sentencias que asumieron esta postura y en especial de las sentencias de unificación de la sección segunda se extraen estos argumentos así:

La vigencia en el tiempo de una interpretación judicial sigue la misma vigencia en el tiempo de la norma que es interpretada, de tal forma que cuando un juez varía una postura jurisprudencial lo hace respecto de una norma jurídica que se encontraba vigente con anterioridad a los hechos que son objeto de decisión, y, por ende, no es cierto que se de aplicación a retroactiva, porque, se reitera, la norma interpretada preexiste al conflicto.

La protección de la Constitución de 1991 se concreta respecto de los derechos adquiridos conforme lo indica el artículo 58 de la Constitución, por lo que esta protección no resulta aplicable a los cambios jurisprudenciales que afecten procesos en curso, toda vez que en estos casos, las partes del proceso no tiene un derecho adquirido, ni mucho menos una situación consolidada, y la mejor prueba de ello es que existe un debate judicial no concluido, razón por la cual la aplicación del nuevo criterio jurisprudencial al proceso en trámite no vulnera derecho alguno.

El derecho no puede ser petrificado, y, por el contrario, su estructura debe permitir adecuarse al cambio social y las nuevas exigencias del contexto en el 
que se aplica, por lo que admitir una vigencia prospectiva supone ir contra la esencia del derecho en su función de regular la sociedad en la que se aplica.

La historia de nuestro sistema y ordenamiento jurídico ha sido consistente en entender que la jurisprudencia en cuanto descubre un significado de una norma que preexiste, rige de manera inmediata para los procesos en curso.

No obstante haberse definido esta regla general de los efectos retroactivos, o, si se quiere por algunos retrospectivos de los cambios jurisprudenciales, al interior de las decisiones del Consejo de Estado esta regla ha encontrado algunos matices, $\mathrm{o}$, dicho de otra manera, se han desarrollo excepciones en las cuales el efecto aplicado es el prospectivo.

En estos supuestos, evidentemente, la tensión entre la justicia material y la legalidad como principios que subyacen a la idea de los efectos retroactivos de estos cambios deben ceder a favor de otros valores o principios constitucionales, que en el asunto concreto tienen un mayor peso y que exigen la aplicación de la nueva subregla jurisprudencial para hechos acaecidos con posterioridad.

Una primera excepción se encuentra en aquellos supuestos donde la nueva ratio o regla jurisprudencial es de índole procesal, eventos en los cuales la misma se aplica para situaciones o hechos ocurridos con posterioridad a la decisión judicial que contiene la nueva regla procesal, y ello se explica en razón de la vigencia del derecho fundamental de acceso a la administración de justicia, pues imponer un requisito de índole procesal que no existía al momento de presentarse la demanda implica restringir la posibilidad que la controversia sea definida desde el punto sustancial, y, en consecuencia, la mejor forma es dar un efecto prospectivo a la sentencia que establece el nuevo requisito procesal.

A título de ejemplo, cabe señalar aquellos asuntos en que se discute el tipo de acción o medio de control que debió adelantarse para resolver la controversia, o la forma de contabilizar el término de caducidad, o incluso la forma de acreditar algún hecho que fue establecido por una subregla jurisprudencia, el efecto en el tiempo deberá ser prospectivo.

La segunda excepción, hace relación a los asuntos de naturaleza electoral en los cuales la nueva regla jurisprudencial (re)interpreta el alcance de una inhabilidad, incompatibilidad o prohibición, pues en estos supuestos la necesidad del efecto prospectivo no deviene sólo del principio de confianza legítima como lo reseñan las sentencias antes descritas, sino que adicional a este valor, el efecto prospectivo se impone en estos casos como salvaguarda del principio democrático, en la medida que los servidores de elección popular fueron elegidos por el sistema democrático que constituye uno de los elementos definitorios de nuestra organización política y,en consecuencia, adquiere un peso de mayor relevancia frente a la regla general del efecto retroactivo, debiéndose en consecuencia aplicar para hechos hacia el futuro, a través de lo que la Sección Quinta ha denominado la jurisprudencia anunciada.

$\mathrm{Y}$ aunque no se conoce de un antecedente jurisprudencial respecto de un supuesto de inhabilidad (re)interpretado en un servidor público no elegido por elección popular, se cree que también aplicaría el efecto prospectivo, dándose primacía al derecho fundamental de acceso a los cargos públicos y al ejercicio del poder político.

Una tercera excepción se materializa en los supuestos del derecho sancionador, en los cuales la nueva regla jurisprudencial resulta más perjudicial para la persona que es objeto del ius puniendi, tal y como se mostró en el caso de pérdida de investidura que se analizó anteriormente, eventos en los cuales el efecto prospectivo también encuentra su fundamentación en un principio constitucional que además constituye una meta-regla de interpretación: el principio de favorabilidad establecido en el artículo 29 de la Constitución.

En estos tres eventos, el derecho de acceso a la administración de justicia, el principio democrático y el

Pensamiento Americano Vol. 14 - No. 27 - p.p. 17-37 • 2021 • Enero - Junio · Corporación Universitaria Americana · Barranquilla, Colombia · ISSN-e: 2745 -1402 $\mathrm{http} / / /$ publicaciones.americana.edu.co/index.php/pensamientoamericano/index 
principio de favorabilidad se imponen en el ejercicio de ponderación frente a los principios de legalidad y universalidad, exigiendo la aplicación de los efectos prospectivos cuando quiera que se encuentre en uno de estos supuestos.

Hasta aquí se puede señalar el estado del arte de las posturas jurisprudenciales de la Jurisdicción Contenciosa Administrativa en torno a la vigencia en el tiempo de los cambios jurisprudenciales y las sentencias de unificación.

Para terminar, resulta oportuno realizar algunas reflexiones finales frente al tema que se ha venido analizando, a efectos de generar algunos planteamientos y propuestas para el debate y la discusión.

Un primer aspecto que resulta relevante para el caso o los supuestos de naturaleza laboral, es la omisión tanto de la Sección Segunda como la Sala Plena de lo Contencioso en analizar la incidencia del principio de favorabilidad laboral previsto en el artículo 53 de la Constitución de 1991 en la determinación de los efectos de un cambio jurisprudencial laboral que resulta regresivo, o si se quiere, menos favorable, pues prima facie, resultaría fácil concluir en una interpretación maximalista del principio de favorabilidad laboral, que la definición del efecto prospectivo o retroactivo estaría supeditado a que uno u otro efecto redundara en beneficio del trabajador, punto sobre el cual, se reitera, nada se indicó en las providencias analizadas.

En segundo lugar, en las sentencias de unificación de la Sección Segunda siguiendo los planteamientos realizados en un auto de ponente del despacho del entonces consejero de estado Dr Danilo Rojas Betancourth (2018), se señalan, en un ejercicio académico, tres supuestos en los cuales se considera que deben operar los efectos prospectivos de los cambios jurisprudenciales así:

- las partes en un litigio hayan fundado sus pretensiones o defensa, según el caso, única y exclusivamente en el precedente vigente al mo- mento de su actuación ante la jurisdicción

- lo bien fundado de dicho precedente no haya sido cuestionado en el trámite del proceso;

- El cambio opere en un estadio procesal en el que resulte imposible reconducir las pretensiones o replantear la defensa pues, en esas circunstancias, la aplicación de la nueva regla jurisprudencial no sólo sorprendería a las partes, sino que, de facto y sin posibilidades de reformular los términos del litigio, dejaría sin sustento la posición jurídica defendida por una de ellas.

Si bien es cierto no se conoce un caso en el cual se haya dado aplicación a uno de estos supuestos, del análisis de estos se puede advertir que en el evento que sean aplicados en los términos planteados, la regla general serían los efectos prospectivos y no los retroactivos.

En efecto, son muchos los eventos en los cuales la tesis del litigio se centra en una postura jurisprudencial que constituye el eje central de la argumentación del demandante, luego conforme a la excepción planteada por la Sala Plena de la Sección Segunda, por esta razón, el efecto debería ser prospectivo, pese a lo cual este planteamiento no fue desarrollado en la sentencia de Sala Plena de lo Contencioso Administrativo del Consejo de Estado que resolvió el asunto de la reliquidación pensional, donde el eje central de la demanda se basada en la tesis jurisprudencial plasmada en la sentencia del 04 de agosto de 2010 , a pesar que la totalidad de los magistrados de la Sección Segunda intervinieron en dicha decisión.

De la misma manera, la tercera excepción según la cual, cuando el cambio jurisprudencial opere en un etapa procesal en la cual no sea posible reconducir las pretensiones o replantear la defensa, los efectos del cambio deberían ser prospectivos, con lo cual en la práctica la mayor parte de los efectos de la decisión serían prospectivos, si se tiene en cuenta que una vez agotada la fase escrita del proceso contencioso ad- 
ministrativo, ya no es posible modificar o reformar la demanda, sumado a la circunstancia que un misma decisión judicial tendría los efectos prospectivos para los procesos que ya superaron la fase escrita, por ejemplo están al despacho para fallo, y retroactivos para los que no han agotado esta fase.

Como se puede visualizar, la lógica de estas excepciones planteadas como discurso en las sentencias de unificación de la Sección Segunda del Consejo de Estado no parecen corresponder con la idea que subyace a los asuntos decididos por las otras secciones del Consejo de Estado, que han definido la regla general de los efectos retroactivos y los efectos retrospectivos para los asuntos de naturaleza procesal, electoral-inhabilidades y sancionatorio conforme se analizó, por lo que se hace necesario que exista un armonización entre los diversos discursos para generar una línea clara que no se preste a confusiones.

Todo el análisis hasta ahora realizado se ha centrado en la determinación de los efectos prospectivos o retroactivos de los cambios jurisprudenciales, pese a lo cual resulta claro que siempre en un cambio jurisprudencial va a existir una transición que genera algún grado de modificaciones a las actuaciones o situaciones en curso, y que de una u otra manera tiene un impacto en la seguridad jurídica y la confianza legítima como valores protegidos por el orden jurídico.

En este orden de ideas, es posible plantear o desarrollar ideas, que mitiguen o reduzcan el impacto delos cambios jurisprudenciales y para ello quizás sea oportuno analizar soluciones o planteamientos que tengan un impacto en el antes de la decisión, pues hasta ahora solo se ha pensado en él después de la misma.

A título de ideas para ser tenidas en cuentay que exploren un camino nuevo, podría pensarse en exigir una mayoría calificada para los cambios jurisprudenciales en las altas cortes, de tal forma que se garantice que un solo voto como sucede-en no pocos casos-termine imponiendo un cambio en las reglas jurídicas.

De la misma manera, se podría imponer como apli- cación de los principios de transparencia y participación, que una vez se determine que hay la posibilidad de realizar un cambio jurisprudencial o proferir una sentencia de unificación, se abra al interior de la Corte o Consejo un espacio para que los diversos actores del tema en decisión puedan intervenir para ofrecer ideas o argumentos antes que la decisión sea tomada, con lo cual además de enriquecer el debate, se advierte a los eventuales afectados de la posibilidad de un posible cambio jurisprudencial, lo cual reduce el elemento de sorpresa o imprevisibilidad.

En esta línea de pensamiento, la Ley 2080 (2021) recién promulgada estableció algunas disposiciones en este sentido.Así, por ejemplo, el artículo 79 que modificó el artículo 271 de la Ley 1437 de 2011 estableció que las decisiones que, por importancia jurídica, trascendencia económica o social, o necesidad de sentar jurisprudencia o precisar su alcance o resolver divergencias en su interpretación o aplicación, deberán ser tomada por la Sala Plena de lo Contencioso Administrativo en asuntos "procesales que sean transversales a todas las secciones del Consejo de Estado." Y pareciera incuestionable que los efectos en el tiempo de las sentencias de unificacióny los cambios jurisprudenciales se subsumen en un asunto procesal que resulta transversal a todas las secciones.

En la misma norma de la (Ley 2080, 2021), se previó en el parágrafo la posibilidad de implementar un mecanismo de publicidad que permita a la comunidad, los jueces y magistrados estar al tanto de los procesos que por cualquiera de las condiciones antes indicadas va a ser definido en una sentencia de unificación, o, incluso que se puedan proponer asuntos o temas para ser definidos.

En las diversas reformas que se han propuesto para la administración de justicia, normalmente se busca ampliar los periodos de los magistrados de alta corte, medida que podría tener un impacto en el tema que se estudia, toda vez que genera una mayor estabilidad en la jurisprudencia por el mayor número de años que los magistrados pueden durar en sus despachos.

Nada impide, que sea el propio legislador quien

Pensamiento Americano Vol. 14 - No. 27 - p.p. 17-37 • 2021 • Enero - Junio · Corporación Universitaria Americana • Barranquilla, Colombia · ISSN-e: 2745-1402 $\mathrm{http} / / /$ publicaciones.americana.edu.co/index.php/pensamientoamericano/index 
dentro del marco de su poder de configuración normativa regule los efectos en el tiempo de las sentencias de unificación y los cambios jurisprudenciales, con lo cual podría ganar en estabilidad y certeza en las reglas expedidas.

En igual forma, la mora judicial es una causa que maximiza con un efecto exponencial los efectos en el tiempo de los cambios jurisprudenciales, pues la demora en decidir los asuntos trae como consecuencia que, en ese largo periodo de tiempo, sean muchos los cambios jurisprudenciales que se presentan y que inciden en la decisión final del proceso.

\section{Conclusión}

Tal y como se señaló en la introducción del artículo, el objetivo del mismo era abordar un tema que ha suscitado un interés académico y práctico reciente, como consecuencia del desarrollo que ha tenido el efecto vinculante de las decisiones judiciales, o si se quiere la teoría del precedente en nuestro derecho y este es: la vigencia en el tiempo de los cambios jurisprudenciales y las sentencias de unificación.

Del análisis realizado se concluye que la intervención del legislador ha sido nula para abordar este tema, y que como en muchos otros asuntos, le ha correspondido al Juez, en este caso, a las diversas secciones y Sala Plena del Consejo de Estado ir fijando los criterios para resolver los conflictos de la aplicación en el tiempo de las decisiones judiciales.

De manera general los efectos o son prospectivos-ratio iuris aplica para el futuro- o son retroactivos- ratio iuris aplica hacia el pasado-, sin que exista un acuerdo en la doctrina o en la teoría jurídica sobre cuál es el mejor efecto, a tal punto que se ha propuesto que sea el Juez en cada caso quien resuelva el efecto que debe tener su decisión judicial.

Del estudio de la jurisprudencia del Consejo de Estado se ha podido establecer que la regla general es que los efectos de las decisiones judiciales que fijan una nueva regla jurisprudencial son por regla general retroactivos, como garantía de los principios de justicia material, legalidad y universalidad, pese a lo cual, en algunos supuestos estos valores deben ceder respecto de otros que en el contexto del caso concreto resultan de un mayor peso; por lo que, a partir de allí se han establecido tres supuestos en los cuales el efecto de la nueva regla jurisprudencial debe ser prospectivo.

En materia de asuntos de naturaleza procesal, el principio del derecho de acceso a la administración de justicia impone que una variación procesal de una subregla jurisprudencial sólo tenga efectos hacia el futuro. De la misma manera, en asuntos de naturaleza electoral en el que se discute la configuración de una inhabilidad o incompatibilidad a partir de una nueva interpretación jurisprudencial, el principio democrático exige que el efecto de la decisión sea prospectivo, como también el principio de favorabilidad en el ejercicio del ius puniendi indica que el efecto de una variación jurisprudencial que puede afectar al sujeto pasivo del poder sancionador del Estado tenga efectos hacia el futuro.

A pesar de que este parece ser el estado del arte, no existe aún un consenso en el Consejo de Estado sobre este tema, el cual debe ser objeto de análisis por la doctrina e incluso merece la intervención del legislador, pero también medidas que maximicen los derechos antes de la toma de la decisión, como la exigencia de una mayoría calificada para cambiar la jurisprudencia, la apertura de procesos de participación previos a la decisión, y la reducción de la mora judicial.

Ante todo, el artículo pretendió generar el debate sobre un tema poco explorado y estudiado, pero con grandes repercusiones en el ejercicio del derecho y que como se indicó en el título del artículo, es un asunto en construcción.

Pensamiento Americano Vol. 14 - No. 27 - p.p. 17-37 • 2021 • Enero - Junio • Corporación Universitaria Americana • Barranquilla, Colombia • ISSN-e: 2745-1402 $\mathrm{http} / / /$ publicaciones.americana.edu.co/index.php/pensamientoamericano/index 


\section{Referencias}

Ajani, G. (2010). Sistemas Jurídicos Comparados. Universidad de Barcelona.

Armenta, K. (2014). Modulación de los efectos temporales de las providencias de unificación del Consejo de Estado en Colombia. Diálogos de Derecho y Política. Diálogos de Derecho y Política 13(6). 47-70. https://revistas.udea.edu.co/index.php/derypol/ article/view/19903/16840

Consejo de Estado. Sala Plena de lo Contencioso Administrativo. Radicado No.11001031500020160318100, C.P. Carlos Enrique Moreno; 01 de agosto de 2017.

Consejo de Estado. Sala Plena de lo Contencioso Administrativo. Radicado No. 52001233300020120014301, C.P. Cesar Palomino Cortes; 28 de agosto de 2018.

Consejo de Estado. Sala Plena de lo Contencioso Administrativo. Radicado No. 7600012331000200002513, C.P. Ruth Estella Correa; 27 de marzo de 2007.

Consejo de Estado. Sección Cuarta. Radicado No. 1100010315000201600038 , C.P. Jorge Octavio Ramírez; 26 de septiembre de 2016.

Consejo de Estado. Sección Primera. Radicado No. 44001233300220160009601, C.P. Hernando Sánchez Sánchez; 08 de junio de 2017.

Consejo de Estado. Sección Quinta. Proceso No. 2015-00051, C.P. Alberto Yepes Barreiro; 7 de junio de 2016.

Consejo de Estado. Sección Quinta. Radicado No. 11001031500020160134401 , C.P. Jorge Octavio Ramírez; 15 de diciembre de 2016.

Consejo de Estado. Sección Quinta. Radicado No. 11001032800020140003400 , C.P. Alberto Yepes Barreiro; 26 de marzo de 2015.

Consejo de Estado. Sección Quinta. Radicado No. 25000233100020110077502, C.P. Alberto Yepes Barreiro;12 de septiembre de 2013.
Consejo de Estado. Sección Quinta. Radicado No.11001031500020150003100, C.P. Susana Buitrago Valencia; 05 de marzo de 2015.

Consejo de Estado. Sección Segunda. Radicado No. 11001031500020190307901, C.P: William Hernández Gómez; 10 de marzo de 2020.

Consejo de Estado. Sección Tercera. Proceso 33945, C.P. Hernán Andrade Rincón; 27 de junio de 2017.

Consejo de Estado. Sección Tercera. Proceso No. 17859, C.P. Carlos Alberto Zambrano Barrera; 18 de abril de 2013.

Consejo de Estado. Sección Tercera. Proceso No. 19.957, C. P. Ruth Stella Correa Palacio; 4 de marzo de 2011.

Consejo de Estado. Sección Tercera. Proceso No. 39947, C.P: Martín Bermudez Muñoz; 02 de marzo de 2020.

Consejo de Estado. Sección Tercera. Proceso SU No. 61033, C.P. Marta Nubia Velásquez Rico; 29 de enero de 2020.

Consejo de Estado. Sección Tercera. Radicado No. 0800123330002013004401, C.P. Danilo Rojas Betancourth; 25 de septiembre de 2017.

Consejo de Estado. Sección Tercera. Radicado No. 2500023260001997139300, C.P. Mauricio Fajardo; 01 de septiembre de 2013.

Consejo de Estado. Sección Tercera. Radicado No. 68001233100020090029501, C.P. Jaime Orlando Santofimio; 04 de septiembre de 2017.

Constitución Política de Colombia [Const]. Art. 230 de julio de 1991 (Colombia).

Decreto Ley 2304 de 1989. (1989, 7 de octubre). Presidencia de la República. https://www.funcionpublica.gov.co/eva/gestornormativo/norma.php?i=6542

Gascón, M. (2015). La Racionalidady el (auto) precedente: Breves consideraciones sobre el fundamento y las implicaciones de la regla del auto-precedente. Universidad Externado de Colombia. 
Ley 100 de 1993. (1993, 23 de diciembre). Congreso de la República. Diario Oficial No 41.148. https://normograma.info/men/docs/ pdf/ley_0100_1993.pdf

Ley 1395/10. (2010, 12 de julio). Congreso de la República. Diario Oficial No 47.768. http://www.secretariasenado.gov.co/senado/ basedoc/ley_1395_2010.html

Ley 1437 de 2011.(2011,18 de enero). Congreso dela República. Diario Oficial No 47.956. http://www.secretariasenado.gov.co/senado/ basedoc/ley_1437_2011.html

Ley 169 de 1896. (1986, 31 de diciembre). Congreso de la República. Diario oficial No 10.235. https://www.funcionpublica.gov.co/ eva/gestornormativo/norma.php?i=17755

Ley 2080 de 2021. (2021, 25 de enero). Congreso de la República. Diario oficial 51.568. http://www.secretariasenado.gov.co/ senado/basedoc/ley_2080_2021.html

Ley 270 de 1996. (1996, 7 de marzo). Congreso de la República. Diario oficial No. 42.745. http://www.secretariasenado.gov. co/senado/basedoc/ley_0270_1996.html

Ley 61 de 1886. (1886, 25 de noviembre). Congreso de la República. Diario oficial No. 6.881 - 6.882. https://www.redjurista.com/ Documents/ley_6l_de_1886.aspx\#/

Ley 617 de 2000. (2000, 6 de octubre). Congreso de la República. Diario Oficial No 44.188. http://www.secretariasenado.gov. co/senado/basedoc/ley_0617_2000.html

López Medina, D. (2006). El Derecho de los Jueces. Universidad de los Andes.

Molfessis, N. (2005). Les Revirements de jurisprudence. Collectif Litec.

Rojas, D. (2018). Jurisprudencia y precedente en Colombia debates de una transición inconclusa. Texto de una conferencia no publicada aún.

Sentencia C-104/93. (1993, 11 de marzo). Corte Constitucional. (Alejandro Martínez Caballero, M. P.) https://www.corteconstitucional.gov.co/relatoria/1993/C-104-93.htm
Sentencia C-836/01. (2001, 9 de agosto). Corte Constitucional. (Rodrigo Escobar Gil, M. P.) https://www.corteconstitucional.gov.co/relatoria/2001/C-836-01.htm

Sentencia SU-047/99. (1999, 29 de enero). Corte Constitucional. (Carlos Gaviria Díaz, M. P.) https://www.corteconstitucional. gov.co/relatoria/1999/su047-99.htm

Sentencia SU-230/15. (28 de abril, 2015). Corte Constitucional. (Jorge Ignacio Pretelt Chaljub C.P.) https://www.corteconstitucional.gov.co/relatoria/2015/su230-15.htm

Sentencia T- 654/15. (2015, 09 de octubre). Corte Constitucional. (Gloria Stella Ortiz Delgado C.P.) https://www.corteconstitucional.gov.co/relatoria/2015/C-654-15.htm

Sentencia T-645/16. (2016, 23 de noviembre). Corte Constitucional. (María Victoria Calle Correa M. P.) https://www.corteconstitucional.gov.co/RELATORIA/2016/C-645-16.htm

Sodero, E. (2004). Sobre el cambio de los precedentes. Isonomía: Revista de Teoría y Filosofía del Derecho 21. 217-251. https:// doi.org/10.5347/isonomia.v0i21.315

Zejalbo, J. (2012). Nuevas Notas Sobre La Retroactividad de la Jurisprudencia. https://www.notariosyregistradores.com/web/ secciones/doctrina/articulos-doctrina/retroactividad-jurisprudencia/

2021, Vol. 14(27) 17-37 @ The Author(s) 2021 Reprints and permission: www.americana.edu.co http://publicaciones.americana.edu.co/index.php/pensamientoamericano/index 
